\title{
La construcción discursiva del acontecimiento "quema de iglesias" en el marco del conflicto mapuche: una mirada desde el análisis del discurso ${ }^{1}$
}

\author{
Pablo Segovia Lacoste ${ }^{2}$ \\ Universidad de Concepción \\ Fernanda Osorio Zúñiga \\ Universidad de Concepción \\ Mariana Aillon Neumann \\ Universidad de Concepción \\ Óscar Basulto Gallegos \\ Universidad Católica de la Santísima Concepción
}

1 Este artículo se llevó a cabo gracias al financiamiento del Proyecto VRID Iniciación 219.062.059-INI de la Universidad de Concepción, titulado "La construcción del "conflicto mapuche" en la prensa escrita: una interpretación desde el Análisis del Discurso".

2 Para correspondencia, dirigirse a: Pablo Segovia Lacoste (psegovia@udec.cl), Universidad de Concepción, Departamento de Español, Casilla 160-C, Correo 3, Concepción, Chile. 


\title{
Resumen
}

Este artículo aborda la construcción discursiva del acontecimiento "quema de iglesias" que se desarrolla en el marco del denominado "conflicto mapuche". Se estudian las formas en que la prensa escrita configura el acontecimiento "quema de iglesias", se caracterizan la representación de los mapuches y se reflexiona sobre el rol de la memoria en la conformación e interpretación de este acontecimiento. La perspectiva asumida corresponde a la del Análisis del Discurso de origen francés, específicamente la línea desarrollada por Siblot (1997), Moirand (2007) y Veniard (2013), y se trabaja sobre un corpus compuesto de textos publicados en distintos periódicos nacionales (El Mercurio, La Tercera, The Clinic, Radio Bío-Bio y Publimetro), entre marzo del año 2016 y enero de 2018.

Palabras clave: Análisis del Discurso, conflicto mapuche, memoria y medios de comunicación.

\section{THE DISCURSIVE CONSTRUCTION OF THE EVENT "BURNING OF CHURCHES" IN THE CONTEXT OF THE MAPUCHE CONFLICT: A LOOK FROM THE DISCOURSE ANALYSIS}

\begin{abstract}
This article addresses the discursive construction of the event «the burning of churches», which occurred in the context of the so-called «Mapuche conflict». This study aims to analyze the ways in which the written press builds the event «burning of churches», to characterize the representation of the Mapuche people and to reflect upon the role of memory in the conformation and interpretation of this event. The selected theoretical approach corresponds to French Discourse Analysis, specifically Siblot's (1997), Moirand's (2007) and Veniard's (2013) strands. The corpus is made of texts published in various national newspapers (El Mercurio, La Tercera, The Clinic, Radio BioBio and Publimetro), dated between March 2016 and January 2018.
\end{abstract}

Keywords: Discourse Analysis, Mapuche conflict, memory and media.

Recibido: 20/03/19 Aceptado: 02/10/19 


\section{INTRODUCCIÓN}

El acontecimiento mediático denominado "quema de iglesias" por la prensa irrumpió con fuerza en el espacio público en marzo de 2016, originando una serie de interrogantes sobre el origen de estos acontecimientos, sus participantes y sus efectos en la sociedad. A través de la televisión nacional circulaban imágenes de iglesias calcinadas, feligreses atónitos y sacerdotes buscando explicación, lo que abrió un amplio debate sobre el uso de la fuerza, la tolerancia religiosa y la violencia que se vive en la zona del denominado "conflicto mapuche".

Desde sus inicios, la prensa categorizó estos acontecimientos mediante una serie de nominalizaciones como "ataques incendiarios contra las iglesias", "atentados" y "seguidilla de atentados incendiarios", proponiendo de esta manera una interpretación de estos acontecimientos. Asimismo, la prensa describió a los autores de estos hechos como "terroristas", "bárbaros", "irracionales", responsabilizando a las comunidades mapuches de lo acontecido.

Para Pinto (2017), los acontecimientos categorizados bajo la nominalización "quema de iglesias" son el resultado de la alta tensión que se vive en la región de La Araucanía entre los diferentes actores políticos, a saber: los mapuches, los agricultores, las empresas forestales, el gobierno y los parlamentarios (de derecha e izquierda). Estos actores van a tener un rol relevante al momento de evaluar y categorizar los acontecimientos señalados y sus participantes, generando de este modo un espacio social y discursivo marcado por fuertes tensiones vehiculadas por medio del discurso. Cabe preguntarse al respecto: ¿cómo se construye el acontecimiento "quema de iglesias" desde un punto de vista discursivo?, ¿cómo la prensa designa a sus participantes? y ¿cuál es el rol de la memoria en la construcción de este acontecimiento?

En vista de lo anterior, este trabajo tiene por objetivo estudiar la construcción del acontecimiento "quema de iglesias" en la prensa escrita desde una perspectiva discursiva. Se busca analizar las distintas formas que, en el discurso, se refieren al acontecimiento "quema de iglesias", cómo se construyen los participantes de los acontecimientos, específicamente a los mapuches, y de qué manera estas formas de nombrar nos remiten a un "dominio de memoria", en el sentido de Courtine (1981) y Moirand (2007).

Se asumirá la perspectiva del Análisis del Discurso de origen francófono, específicamente la línea desarrollada por Siblot (1997), Moirand (2007) y Veniard (2013), que se apoya en la teoría de la nominación o el "acto de 
nombrar" los acontecimientos en el mundo mediático, así como también en las reflexiones sobre el rol de la memoria en el discurso.

El corpus de esta investigación está compuesto de cuarenta y cinco discursos correspondientes a géneros distintos (noticias, editoriales, columnas de opinión y entrevistas) de los periódicos El Mercurio, La Tercera, The Clinic, Radio Bio-Bio y Publimetro, entre marzo del 2016 y enero de 2018.

El trabajo está organizado en cinco partes. El primer apartado aborda una contextualización histórica y social del tema. El segundo desarrolla el marco conceptual y el tercer se enfoca en cuestiones metodológicas como la conformación del corpus. El cuarto apartado está consagrado a los análisis y el quinto aborda algunas consideraciones generales a modo de conclusión.

\section{EL CONTEXTO HISTÓRICO DEL ACONTECIMIENTO "QUEMA DE IGLESIAS”}

El acontecimiento designado como "quema de iglesias" tiene su origen en marzo de 2016 y desde sus aparición se caracterizó por su intensa producción mediática. Las imágenes que circulaban en la prensa exhibían iglesias calcinadas, feligreses angustiados y párrocos tomándose la cabeza en búsqueda de explicaciones. El ministro del interior de ese entonces, Jorge Burgos, calificó estos acontecimientos como un "acto de una brutalidad ya llevado al extremo" (Radio Cooperativa, 26/04/2016), y con respecto a los autores de estos hechos, la autoridad se refirió de este modo: "Tenemos antecedentes de que son los grupos delincuenciales de siempre que vienen operando" (Radio Cooperativa, 26/04/2016). Por su parte, el presidente del congreso evangélico de la provincia de Arauco, Daniel Monsalve, declaró tener antecedentes de que "hay gente evangélica involucrada en los problemas que se generan" (El Mercurio, 17/04/2016), apuntando a la relación entre grupos religiosos y mapuches radicalizados.

Según la prensa escrita, en el lugar de los hechos fueron encontrados panfletos que hacían alusión al llamado "conflicto mapuche", específicamente a favor de la liberación de los denominados "presos políticos mapuches" y de la reivindicación territorial de las comunidades. De acuerdo con la prensa y la policía, el autor de estos panfletos sería el grupo Weichan Auka Mapu, 
que en español significa "Territorio rebelde en lucha", quienes serían los responsables de los incendios contra iglesias y camiones.

Cabe señalar que apenas se conoce sobre la identidad de este grupo. Mediante un comunicado público aparecido en el sitio www.werken.cl ${ }^{4}$, esta organización se hace responsable de la quema de veintinueve camiones y de otras actividades vinculadas, que ellos denominan "acciones de sabotaje". Para el exintendente de la IX región, Francisco Huenchumilla, esta asociación estaría formada por exintegrantes de la Coordinadora Arauco Malleco ( $E l$ Austral, 3/9/2017), organización designada como la más "radical" al interior del movimiento mapuche.

Miguel Hernández, otro exintendente, opina de manera similar a Huenchumilla. Para este actor político, "se trata de un grupo escindido de la CAM, radicalizado, que opera desde la provincia de Arauco y que ha ido extendiendo su influencia hacia la región de Los Ríos", según declaraciones publicadas en el periódico El Austral del 3/9/2017. De acuerdo con este periódico, perteneciente al conglomerado El Mercurio S.A. ${ }^{5}$, el grupo Weichan Auka Mapu operaría en la clandestinidad, sin un rostro reconocible. $\mathrm{Su}$ forma de actuar consiste en la realización de "actos de sabotaje" contra los grandes latifundistas, las empresas forestales, los proyectos energéticos, los representantes del capital financiero en la zona y las iglesias católicas, tal como lo argumenta esta organización en un comunicado publicado en el sitio werken.cl' .

En el documento señalado, Weichan Auka Mapu dirige sus críticas contra el obispo de la diócesis de Villarrica, Francisco Stegmeier, quien ordenó el desalojo del Seminario San Fidel de Padre las Casas. Para la revista Qué

Existen otras traducciones para este nombre propio, como "Lucha del territorio rebelde". Medio de comunicación virtual que publica noticias concernientes al pueblo mapuche.

El Mercurio S.A. es un conocido medio de comunicación de línea conservadora y perteneciente, desde sus inicios, a la derecha política chilena. Sus orígenes se remontan al año 1827 en Valparaíso y al año 1900 en Santiago. Periódico fundado por Agustín Edwards, miembro de la oligarquía capitalina de Chile. El conglomerado El Mercurio S.A. posee, además del diario El Mercurio, múltiples diarios regionales y radios a lo largo de Chile.

6 "En la actualidad no es casualidad que la iglesia católica sea dueña de todo el magisterio en la Araucanía y que cada escuela sea su bastión económico. Es de público conocimiento la acción de ofensa llevada a cabo por la iglesia católica en contra de un Lof en lucha. Ante la agresión contra cualquier Lof a lo largo del Wallmapu reaccionaremos con nuestro deber implacable imponiendo justicia. Es por ello que ante la irresponsable actitud de un sacerdote de origen alemán de nombre Francisco Stegmeier, hacia uno de los Lof Mapuche, lo cual usando la prepotencia que lo caracteriza ordenó desalojar un Lof de sus tierras que por generaciones les pertenece" (20/04/2016). Disponible en: http://werken.cl/comunicado-de-alianza-organicaweichan-auka-mapu-reivindican-lucha-armada-y-mas-de-una-treintena-de-sabotajes/ 
$\mathrm{Pasa}^{7}$, el desalojo del Seminario San Fidel, ocupado desde 2012 por una comunidad mapuche, habría sido el origen del descontento que concluyó con la destrucción de iglesias católicas y evangélicas.

La figura cuestionada, tanto por las comunidades mapuches como por dirigentes de diferentes sectores políticos, es el obispo Francisco Stegmeier, ligado al Opus Dei (Monckeberg 2003). En efecto, su nombre se encuentra en diferentes panfletos encontrados, según la prensa, en el lugar de los sucesos, en la que se responsabiliza a este obispo de los acontecimientos. Bajo esta óptica, la quema de iglesias católicas se entendería como una reacción al desalojo del Seminario San Fidel y contra la figura de Stegmeier, lo que refleja el clima de tensión que se vive en la Araucanía, tal como lo señala Pinto (2017).

\section{EL ACONTECIMIENTO “QUEMA DE IGLESIAS" COMO PARTE DEL DENOMINADO "CONFLICTO MAPUCHE"}

Según la mayoría de los historiadores (Pinto 2015; Saavedra 2002; Bengoa 2000), el origen del conflicto mapuche se remonta a fines del siglo XIX cuando el Estado chileno ocupó militarmente el territorio araucano, iniciando una guerra contra los autóctonos. Esta guerra se denominó "Pacificación de la Araucanía" y corresponde a la contrapartida de las acciones desarrolladas en Argentina contra los mapuches bajo el nombre de "Conquista del Desierto".

Antes de la ocupación de la Araucanía, los mapuches vivían en alrededor de diez millones de hectáreas (Mariman 2006; Bengoa 2000), reconocidas por diferentes tratados llamados "parlamentos", firmados entre el Imperio español y los mapuches, y luego, entre el naciente Estado de Chile y los mapuches. Sin embargo, a partir de 1860 se desconocieron estos tratados, y el joven Estado chileno, luego de haber triunfado en la Guerra del Pacífico, llevó a cabo la ocupación de los territorios al sur del Bío-Bío, desencadenando una guerra contra los mapuches. Según Bengoa (2000), se trata de uno de los episodios más negros de la historia de Chile. Las consecuencias de este acontecimiento fueron dramáticas: la pérdida del territorio, el robo

7 Revista de tendencia conservadora ligada a los opositores de Salvador Allende. Desde 2018, la revista adopta un formato digital. 
de animales y ganado, el empobrecimiento de la población mapuche y la migración hacia las ciudades en busca de trabajo ${ }^{8}$.

Según Pinto (2003), durante este periodo se desarrolló una "ideología de la ocupación", es decir, un conjunto de creencias que mezclaba el antiindigenismo, la teoría de razas (superior e inferior) y la expansión de la nación más allá de las fronteras. Esta ideología se manifestó en la construcción de un "otro" negativo, percibido como una amenaza para el desarrollo del joven estado chileno. En esta línea, el diario El Mercurio favoreció el desarrollo de esta ideología de la ocupación, debido a que promovió construcciones estereotipadas sobre el mapuche que funcionaron como un argumento para justificar la ocupación militar y la guerra llevada a cabo por el Estado de Chile ${ }^{9}$. En el lenguaje de Pinto (2003), se pasa de la inclusión a la exclusión de los autóctonos del territorio nacional.

Posterior a la ocupación militar, se inicia un largo periodo de lucha con el objetivo de recuperar su territorio y sus recursos perdidos. La historiografía da cuenta de los múltiple esfuerzos (Pinto 2015; Saavedra 2002; Bengoa 2000) de diferentes organizaciones mapuches (Sociedad Caupolicán Defensora de la Araucanía, La Federación Araucana, Asociación Nacional Indígena) para llevar a cabo este objetivo a través de la institucionalidad ${ }^{10}$.

Esa fue la tónica durante todo el siglo XX, hasta la llegada al poder de Salvador Allende, quien, mediante una serie de reformas, mejoró sustancialmente la calidad de vida de los mapuches (Saavedra 2002). Sin embargo, esta situación fue revertida bajo la dictadura de Augusto Pinochet. Diferentes organizaciones mapuches, ligadas a los partidos de izquierda, fueron perseguidas, y la dictadura militar impuso un decreto que permitía la división de las tierras y la apertura al capital forestal.

En 1990, con el regreso de la democracia, se genera un nuevo escenario político que favorece las reivindicaciones de tierra de los mapuches. A nivel internacional, se conmemoró los 500 años del "Descubrimiento de América" y la ONU declaró 1993 como el Año Internacional de las Poblaciones Indígenas del Mundo ${ }^{11}$. A nivel nacional, el Estado de Chile se comprometió a

\footnotetext{
Según Pablo Mariman (2006), otra consecuencia importante fue la pérdida de autonomía de los mapuches sobre su propio territorio, que pasa ahora a ser administrado por el Estado de Chile y los propietarios privados.

9 "Todo lo ha gastado la naturaleza en desarrollar su cuerpo (el de los mapuches), mientras que su inteligencia ha quedado a la par de los animales de rapiña, cuyas cualidades posee en alto grado, no habiendo tenido una emoción moral" (El Mercurio, 24 de mayo de 1859).

10 Cabe señalar que hubo parlamentarios mapuche, como el caso de Venacio Cuñuepan, quien fue diputado del Partido Conservador bajo el gobierno de Carlos Ibáñez del Campo.

11 Véase http://www.un.org/es/events/indigenousday/background.shtml
} 
mejorar las condiciones de los indígenas ${ }^{12}$ y promulgó la ley indígena 19.253 , que otorga un conjunto de beneficios econónimos y sociales a estos pueblos. Esta ley, mediante su organismo llamado CONADI, inicia un proceso de distribución de tierras a un conjunto de organizaciones indígenas amparadas en la institucionalidad. Sin embargo, a juicio de la organización Consejo de Todas las Tierras (Saavedra 2002), esta ley se vio sobrepasada por una serie de hechos, dejando entrever la incapacidad legal para responder a las necesidades de los pueblos indígenas (demanda de mayor autonomía, mayor reconocimiento político, etc.).

En 1997 ocurre un acontecimiento importante que originó, en palabras de Levil Chicahual (2006), "un nuevo ciclo de movilizaciones" en lo relativo al movimiento mapuche. Se trata del "acontecimiento Lumaco"13, que corresponde a un conjunto de acciones dirigidas por dos comunidades mapuches en la zona de Lumaco, una de las comunas más pobres de la Araucanía, que terminó con la quema de varios camiones de propiedad de Forestal Arauco. Según Tricot (2013), esto dio origen a un proceso de radicalización del movimiento mapuche, debido a que significó un cambio de estrategia política del movimiento mapuche que incluyó el uso de la fuerza acompañado de un discurso rupturista contra el Estado chileno. A partir de estos acontecimientos, surge una organización llamada Coordinadora Arauco Malleco (CAM), que canaliza estas demandas mediante métodos radicales.

A nuestro juicio, el acontecimiento "quema de iglesias" se enmarca dentro del proceso de radicalización del movimiento mapuche (Tricot 2013) iniciada en 1997, profundizando de esta manera las tensiones entre los diferentes actores en la región de la Araucanía. Esto se puede evidenciar en dos dimensiones: la dimensión discursiva que dice referencia con las demandas de autonomía territorial, que se materializan con fuerza a partir de 1997, y la dimensión fáctica, en la que la acción (quemar iglesias) sigue el patrón de acciones realizadas con anterioridad (quema de camiones y quema de maquinaria forestal).

12 El expresidente de Chile, Patricio Aylwin, señaló el 18 de enero de 1991 que su gobierno va a establecer una relación diferente con los pueblos indígenas. Véase el Discurso de S.E. el Presidente de la República, Patricio Aylwin Azócar, en clausura del Congreso Comisión de Pueblos Indígenas (18/01/1991). Disponible en: http://fundacionaylwin.cl/discursos/ PRES_207.pdf

13 Véase el artículo de Pairicán (2013). 


\section{MARCO TEÓRICO}

\subsection{LA TEORÍA DE LA NOMINACIÓN EN EL DISCURSO}

Nombrar los objetos del mundo y las diferentes problemáticas que esto implica (¿cómo nombro los objetos?, ¿qué relaciones establezco entre las palabras y las cosas?, ¿a qué tipo de representaciones nos remite el objeto nombrado) forma parte de un largo debate que, según Branca-Rosoff(2007), nos remite a los orígenes de la humanidad.

Desde la lingüística, Kleiber (1984) ha reflexionado sobre esto tomando como eje la relación entre el lenguaje y el mundo. Para este autor, el referente o lo real del mundo corresponde a un aspecto esencial en la construcción del sentido, rompiendo de este modo con la tradicción sauseriana que propone la inmanencia del signo lingüístico (la lengua en sí misma y por sí misma). Kleiber (1984), apoyándose en la semántica referencial, realiza una distinción entre designación y denominación, que ha inspirado a varios autores que abordan esta problemática ${ }^{14}$. Para este autor, la designación hace referencia a una relación inestable entre una expresión lingüística y un objeto de la realidad. Por el contrario, la denominación hace referencia, según Kleiber (1984), a la relación estable entre un vocablo y un elemento de la realidad. Bajo esta lógica, la estabilidad o inestabilidad de la relación entre las palabras y los objetos del mundo estaría sujeta al reconocimiento que esta posee al interior de una comunidad lingüística. De esta manera, por ejemplo, los acontecimientos en torno a la quema de iglesias en La Araucanía pueden ser designados como "actos vandálicos", "acción de sabotaje" o "atentado contra los derechos humanos". Por el contrario, la denominación da cuenta de una estabilidad semántica de un objeto, como por ejemplo en el caso chileno, denominar "fiestas patrias" a los acontecimientos celebrados durante el 18 y 19 de septiembre.

Cabe señalar que esta distinción se realiza sobre todo en el marco de la lexicografía y de la lingüística de la lengua, donde el foco es la semántica lexical. Sin embargo, desde la lingüística del discurso, esta distinción no resulta tan operativa, debido a que el sentido de los enunciados no son de orden gramatical, sino el resultado de las asociaciones de elementos a nivel textual y enunciativo (Bonnafous y Tournier 1995). Como lo plantea Moirand 
(2007), los límites entre estabilidad e inestabilidad de la relación entre las palabras y los objetos del mundo son, a veces, difusos en el discurso.

Lo que nos interesa de las nociones de denominación y designación son fundamentalmente dos cosas. En primer lugar, que ambas nociones hacen referencia a la estabilidad o inestabilidad de las palabras en una dinámica discursiva. Es decir, más allá de esta distinción que establece Kleiber (1984), lo fundamental resulta, para nosotros, cómo las palabras son definidas, reformuladas y cuestionadas por los diferentes locutores cuando hacen referencia a hechos o acontecimientos dudosos o cuya existencia está sujeta a cuestionamientos, lo que nos situa en un "paradigma de la designación", en el sentido de Mortureux (1993) $)^{15}$. En segundo lugar, las nociones de denominación y designación mantienen una relación estrecha con la noción de nominación, propuesta por Siblot (1997), lo que es de gran importancia para el Análisis del Discurso de origen francés. Para Détrie, Siblot y Vérine (2001: 205), se entiende por nominación,

[e]l acto por el cual un sujeto nombra en el discurso, dicho de otro modo, categoriza un referente insertándolo en una clase de objetos identificados en el léxico, a menos que intente innovar con un neologismo. La dimensión performativa de este gesto originario de nominación es, entonces, evidente, y los semánticos lo denominan coloquialmente como el acto de bautizar ${ }^{16}$.

Bajo esta óptica, la nominación está sujeta a una dinámica discursiva y reposa en la subjetividad del sujeto enunciador que despliega un punto de vista y que mantiene una relación particular con los objetos del mundo. Este aspecto resulta fundamental, dado que, como señala Siblot (2001), "a falta de poder nombrar el objeto 'en él mismo y por él mismo', lo nombro tal como me aparece y me concierne [...]. Así, cuando creo nombrar el objeto mismo es mi relación con él lo que en realidad nombro"17.

De este modo, el sujeto enunciador mediante el acto de nombrar establece y nutre una relación con los objetos del mundo, que puede ser de acercamiento o distancia. Esto explica que un mismo objeto del mundo, un referente, puede ser nombrado de diferentes maneras según la posición que ocupa el sujeto enunciador en un contexto dado. Por ejemplo, en el ámbito del conflicto entre el Estado de Chile y el pueblo mapuche, un

\footnotetext{
Volveremos sobre esto en el apartado 4.2.

Nuestra traducción.

Ídem.
} 
acontecimiento puede ser nombrado como "pacificación de Araucanía", "guerra de exterminio" u "ocupación militar", lo que da cuenta de la posición que toma el sujeto enunciador a propósito de este acontecimiento y de los valores que moviliza en este acto de nombrar. De manera similar, un actor puede ser designado como "rebelde", "terrorista", "héroe" o "luchador", lo que implica, al igual que en el ejemplo anterior, una posición que toma el sujeto enunciador y de ciertos valores que compromete en su discurso.

\subsection{NombraR LOS ACONTECIMIENTOS EN EL MUNDO MEDiÁtiCO}

La operación de nombrar, categorizar los acontecimientos en la prensa es un objeto complejo (Veniard 2013). Se trata de reunir en una sola expresión lingüística una serie de acontecimientos diferentes a través de la actividad discursiva. Como una foma de abordar esta complejidad, Quéré (2013) propone distinguir entre "acontecimiento existencial", es decir, un hecho que existe independiente del discurso y un "acontecimiento objeto", es decir, cuando un acontecimiento es tomado por el discurso y se integra a la dinámica de los medios de comunicación. Esta distinción es provechosa para el Análisis del Discurso, debido a que permite resaltar el rol del discurso en la construcción de los acontecimientos y en su significación en el seno de una comunidad lingüística.

De acuerdo con Wolton (1995), los medios de comunicación están sometidos a la "tiranía del instante", lo que implica trabajar y procesar los acontecimientos de actualidad simultáneamente con el desarrollo de los hechos noticiosos. Esta imposición obliga a los redactores de noticias y a los editores de prensa a nombrar los acontecimientos rápidamente, para lo cual recurren generalmente a construcciones preexistentes listas para ser empleadas, "donde las expresiones estereotipadas proliferan" (Calabrese y Rosier 2005: 36). Muchas veces se crean neologismos para categorizar los acontecimientos que poseen un impacto social en la comunidad ${ }^{18} \mathrm{o}$ se agrega un nuevo contenido proposicional a un vocablo, logrando que este pierda su sentido original y adquiera otro ${ }^{19}$.

18 Tal es el caso en Chile de la palabra "portonazo", que permite dar cuenta de un tipo de delito que implica el robo de un automóvil cerca de un portón.

19 Véase en el caso chileno el sentido que adoptó la palabra "transantiago", que originalmente designaba a un sistema de transporte público en Santiago y que actualmente se concibe como un fracaso o un signo de mala organización. 
Estas expresiones utilizadas, generalmente nombres propios, nominalizaciones y construcciones polilexicales ${ }^{20}$, circulan en el mundo mediático y de esto depende su grado de fijación a nivel discursivo: "mientras más circula una expresión, más se estabiliza, más llega a ser reconocible y más se fija", señalan Calabrese y Rosier (2005:36). De esta manera, como lo remarcan estas autoras, un término se impone como algo natural, dado, borrando el origen enunciativo del término y naturalizando otros sentidos asociados como resultado de la circulación mediática.

En lo que respecta al denominado "conflicto mapuche", la prensa de los años noventa utilizó la expresión "conflicto mapuche" y "cuestión indígena" en lugar de otras denominaciones más explicativas como "conflicto chilenomapuche" (Hirt 2001) o "conflicto étnico chileno mapuche" (González 2012). Al momento de la circulación mediática del término "conflicto mapuche", diferentes intelectuales mapuches y no mapuches, entre ellos Pablo Marimán, José Bengoa, José Marimán, denunciaron la opacidad de esta expresión, debido a que ocultaba a otros agentes del conflicto como el Estado de Chile, los agricultores y las empresas forestales. Desde una dimensión discursiva, el sintagma "conflicto mapuche" condensa una serie de acontecimientos variados en una expresión fácil de recordar, que otorga significado e instaura un "dominio de memoria" (Moirand 2007) sobre hechos y decires en torno a este ámbito, cuyo eje central lo otorga el término clasificador "conflicto". La utilización de este término categoriza el acontecimiento dentro de una clase de objetos reconocibles por los lectores. Esto permite activar una serie de elementos asociados, tales como batalla, estrategia, heridos, atentados, violencia, armas (Segovia Lacoste 2015, 2016), que se inscriben al interior de una semántica de la guerra (Segovia Lacoste 2005).

La circulación discursiva del sintagma "conflicto mapuche", que originalmente aparecía entre comillas y acompañada de la expresión "el denominado" o "el llamado", se fue naturalizando y perdió las comillas en la prensa escrita tradicional. Salvo en semanales de prensa alternativa, de preferencia de izquierda, la prensa escrita chilena adoptó el sintagma "conflicto mapuche" sin comillas y sus derivados "conflicto indígena", "zona del conflicto mapuche". El contenido proposicional que acompañaba al sintagma "conflicto mapuche" hacía referencia a hechos categorizados de violentos cuyos responsables eran los mapuches ${ }^{21}$.

20 Véase el empleo de "fórmula discursivas" en el sentido de Krieg-Planque (2009a), entendida como expresiones estables y concisas que en un momento determinado condensan y cristalizan posiciones políticas y sociales.

21 Véase el trabajo de Merino et al. (2007). 
En 2016, cuando surgen los acontecimientos que involucraron incendios de iglesias católicas y evangélicas en la región de La Araucanía se generó de inmediato una serie de cuestionamientos y de interrogantes sobre el origen de estos actos y sus repercusiones. Se desconocía a los autores de tales hechos, no se entendían los motivos, y las imágenes en televisión de iglesias calcinadas generaron un gran impacto en la opinión pública. La prensa escrita tradicional utilizó las siguientes nominalizaciones para referirse a estos acontecimientos: "quema de iglesias", "atentados incendiarios a templos", "delito de incendio", "seguidillas de ataques incendiarios", entre otras. Se trataba de dar inteligibilidad a esta serie de sucesos calificados de "incomprensibles" por la Iglesia Católica. El procedimiento discursivo utilizado para estos efectos fue reportar la voz de los diferentes locutores (discurso referido), quienes, con mayor o menor legitimidad en el mundo social, se referían al tema. De este modo, la prensa escrita utilizó nominalizaciones (derivadas de verbos y adjetivos) para dar cuenta de la caracterización del acontecimiento y sus efectos, en la que se incluían testimonios de los actores. Este último aspecto contribuye a la dramatización de la noticia, fenómeno que ha sido estudiado ampliamente por diferentes autores (Charaudeau 2003; Moirand 2007), que resaltan la preponderancia del componente emocional (el pathos en el lenguaje aristotélico) en la construcción del relato periodístico.

\subsection{La noción De MEMoria en el AnÁlisis del Discurso}

Desde la perspectiva francesa del Análisis del Discurso, las reflexiones sobre la memoria han sido una preocupación constante ${ }^{22}$. A partir de los trabajos de Courtine (1981), se ha iniciado una rica reflexión que se nutre de la historia y de la filosofía, y que vincula la noción de memoria a las condiciones sociales de producción de los discursos (Paveau 2006). Pero el concepto de memoria genera ciertas dificultades al momento de operacionalizarlo en lingüística "porque ella [la memoria] no se deja definir ni circunscribir por uno de sus pares antónimos tan prácticos en ciencias humanas, como historia/memoria, sobre el cual se apoyan fructuosamente historiadores y filósofos"23 (Paveau 2006: 85). Visto lo anterior, numerosos analistas del

22 Cabe señalar que, desde la perspectiva anglosajona del Análisis del Discurso, específicamente desde el Análisis Crítico del Discurso y la Lingüística Sistémico Funcional, se han desarrollado numerosos trabajos en esta área. Para una mayor profundización, véase Achugar (2011).

23 Nuestra traducción. 
discurso han trabajado en la identificación de ciertas huellas lingüísticas de la memoria en la superficie textual.

Una de las autoras en esta línea es Sophie Moirand, quien estudió diferentes acontecimientos (epidemias, huelgas y catástrofes naturales) en la prensa escrita francesa y constató que en los medios de comunicación se tiende a vincular diferentes acontecimientos a través de una serie de redes semánticas que van creando un "dominio de memoria". Según Moirand (2007), la prensa escrita, lejos de presentar los acontecimientos de manera efímera, los relaciona a lo largo del tiempo y contribuye de esta manera a construir un "memoria interdiscursiva" propia de los medios de comunicación. Bajo esta lógica, la "memoria interdiscursiva" corresponde a una serie de relaciones semánticas entre acontecimientos distintos, vinculados por la prensa, que permiten construir "un aire de familia" (Moirand 2007) ${ }^{24}$ entre los diferentes acontecimientos reportados por la prensa. El sustento teórico de esta noción se encuentra en el dialogismo de Bajtín y en las reflexiones de Courtine (1981) sobre la "memoria discursiva", quien señala que la memoria se inscribe en el discurso e implica "la existencia histórica de un enunciado" (Courtine 1981).

Entonces, Moirand $(2003,2007)$ profundizando en lo ya planteado por Courtine (1981), afirma que la memoria se inscribe en el discurso a través de formas lexicales (nombres propios, adjetivos, nominalizaciones, topónimos, cronónimos) y ciertas construcciones sintácticas (expresiones idiomáticas, colocaciones). Estas formas constituyen "gatilladores" de otros acontecimientos que pueden pertenecer a "un tiempo largo", en el sentido de Braudel (1986), como también a acontecimientos recientes. Para este autor (1986), "el tiempo largo" corresponde a estructuras sociales, políticas y económicas permanentes en el tiempo y que permiten explicar los sucesos que surgen a diario en una sociedad. De este manera, la memoria inscrita en las formas léxicas (Moirand 2003,2007) permite activar y restituir imágenes pertenecientes a otros periodos históricos, lo que implica en el lenguaje de la autora (2007) una "memoria de los hechos", es decir, los acontecimientos reconocidos por una comunidad humana (un terremoto, una guerra, un campeonato mundial), y una "memoria de los decires", es decir, los discursos de los distintos sectores a propósito de estos acontecimientos.

24 La autora expone numerosos ejemplos en sus análisis sobre este concepto, tales como "E1 11 de septiembre de las finanzas", "Un pequeño mayo 68 de las periferias", "Es el Katrina de los desastres sociales". Aquí se evidencian dos hechos relacionados, en el que uno de los acontecimientos reconocibles por los lectores (11 de septiembre, mayo 68 y Katrina) contribuye a dar inteligibilidad al otro acontecimiento desconocido por los lectores. 
De acuerdo con Moirand (2007), los medios de comunicación contribuyen en la formación de una "memoria colectiva", en el sentido de Halbwachs (1997), a través de la repetición, la reformulación, el recuerdo y el olvido de ciertas construcciones discusivas a propósito de un acontecimiento dado.

Visto de este modo, la noción de memoria resulta fructífera para comprender la relación entre el lenguaje y sus condiciones históricas de producción, en la medida en que genera un tejido semántico reconocible entre los hablantes y que participa activamente en la producción del sentido del discurso.

\section{LA CONSTRUCCIÓN DE UN CORPUS DE TRABAJO}

El corpus de trabajo está compuesto por cuarenta y ocho textos de distintos géneros discursivos de los periódicos El Mercurio ${ }^{25}$ y La Tercera ${ }^{26}$, el semanal The Clinic ${ }^{27}$ y artículos de la plataforma web de la Radio Bio-Bió ${ }^{28}$ y de diario digital Publimetro $^{29}$, publicados entre marzo del año 2016 y enero de 2018.

El criterio de selección de textos es de orden temático. Se escogieron textos (noticias, editoriales, reportajes, entrevistas y columnas) que abordaron el tema de los incendios en las iglesias de La Araucanía. Como se puede evidenciar, se utilizaron distintos géneros discursivos. Esto se basa en el supuesto que señala que para abordar el sentido de los acontecimientos

25 Véase la nota 3.

26 La Tercera es un periódico chileno de circulación diaria de tendencia editorial más centralista. En la actualidad es uno de los periódicos de mayor circulación en Chile y mantiene una dura competencia con El Mercurio, de mayor tradición.

27 The Clinic es un semanario chileno, caracterizado por mezclar sátira y humor político con crítica social. Fue creado en 1998 por Patricio Fernández. Su eslogan, Firme junto al pueblo, fue copiado del desaparecido diario chileno Clarín, cerrado tras el golpe de Estado de 1973, lo que evidencia la clara línea editorial de izquierda.

28 Radio Bío-Bío es una estación radial chilena, fundada en 1966, con base en la ciudad de Concepción y con sedes en varias otras ciudades. En el año 2009, la Radio Bío-Bío reinaugura su sitio web, en el que comienzan a publicar noticias y acontecimientos. Hoy es uno de los sitios de noticias más visitados del país con millones de visitas virtuales y con más de dos millones de seguidores en Facebook y Twitter.

29 Publimetro es un diario de distribución gratuita, fundado en 1995, que posee una versión en papel y digital. Este medio es de propiedad del holding sueco llamado Metro International y está presente en numerosos países de América Latina. 
sociales se debe realizar a través de la diversidad de sus prácticas discursivas que se manifiestan en géneros discursivos diferentes. Con esto, podemos dar cuenta de la "heterogeneidad enunciativa" de los textos (Moirand 2007), lo que contribuye a estudiar los diversos sentidos de un corpus.

El procedimiento para abordar el corpus consiste en analizar los textos sin ayuda de software, siguiendo tres pasos. En un primer momento, se clasificaron los textos de acuerdo al género discursivo, tomando en cuenta los aspectos enunciativos (modo elocutivo y delocutivo) y las restricciones propias del género discursivo. Posteriormente, se abordaron los distintos elementos presentes en la superficie textual, que constituyen "observables" de la actividad discursiva (nominalizaciones, verbos, construcciones idiomáticas, construcciones sintácticas, etc.), en el sentido de Moirand (2007). Finalmente, se articularon estos "observables" (Moirand 2007) con los diferentes aspectos sociales y culturales, con el fin de construir una interpretación pertinente en relación con la disciplina en cuestión ${ }^{30}$.

Cabe señalar que estas tres etapas para trabajar el corpus no se dan de manera lineal y progresiva. Existe un constante movimiento de ida y vuelta entre las categorías teóricas preestablecidas y las particulares que presenta el corpus estudiado.

\section{ANÁLISIS DEL CORPUS}

En este apartado se llevará a cabo el análisis de los textos. En primer lugar, se abordará la construcción discursiva del acontecimiento "quema de iglesias" centrándonos en los temas o tópicos principales desarrollados en el corpus. A continuación, analizaremos la construcción de los participantes del acontecimiento "quema de iglesias", específicamente de "los mapuches". En último lugar, se reflexionará sobre el aporte de la noción de memoria al estudio del acontecimiento "quema de iglesias".

30 Esta metodología de trabajo fue utilizada con anterioridad en Segovia Lacoste et al. (2018). 


\subsection{LA CONSTRUCCIÓN POR MEDIO DEL DISCURSO DEL ACONTECIMIENTO "QUEMA DE IGLESIAS"}

Los temas o tópicos centrales del corpus fueron categorizados en cinco proposiciones: el acontecimiento "quema de iglesias" como acción reprochable, el acontecimiento "quema de iglesias" como terrorismo o acción terrorista, el acontecimiento "quema de iglesias" como acción violenta, el acontecimiento "quema de iglesias" como acción de un agente perverso y el acontecimiento "quema de iglesias" como parte del conflicto mapuche.

El procedimiento para seleccionar estas proposiciones fue de orden semántico y consiste en sintetizar una serie de enunciados relacionados entre sí bajo una proposición.

El acontecimiento "quema de iglesias" como acción reprochable

(1) "En estos hechos perversos e innobles" (El Mercurio, 2 de mayo de 2016; Humberto Lagos, Director Nacional de Asuntos Religiosos).

(2) "Estos hechos tan deleznables" (El Mercurio, 2 de mayo de 2016; Humberto Lagos, Director Nacional de Asuntos Religiosos).

(3) "Estos hechos cobardes no tienen nada que ver con reivindicaciones históricas del pueblo mapuche" (Publimetro, 11 de junio de 2016; Mahmud Aleuy, Subsecretario del Interior).

Uno de los tópicos dominantes cuando se describen los acontecimientos relacionados con la "quema de iglesias" corresponde a la evaluación negativa que le otorga la mayoría de los locutores. El rechazo a la violencia contra las iglesias reunió tanto a los locutores autorizados, es decir, que detentan un grado de poder $^{31}$ (parlamentarios de izquierda y derecha, jueces, fiscales, policías, autoridades de las diferentes iglesias), como a locutores carentes de poder. Cabe destacar que numerosas organizaciones mapuches condenaron los actos de violencia contra las iglesias, desmarcándose de este modo del discurso de la agrupación Weichan Auka Mapu, que reivindica estos actos y los califica como "acciones de sabotaje". Incluso, la organización mapuche Coordinadora Arauco Malleco (CAM), designada por la prensa y los organismos de inteligencia como una de las más radicales, cuestionó las

31 Se entenderá por poder la capacidad de ejercer control o influencia sobre una persona o un grupo determinado. 
acciones vinculadas con la quema de iglesias ${ }^{32}$, debido a que "deslegitima" la política llevada a cabo por esta organización.

Lo que nos interesa de este apartado es la evaluación negativa que le otorgan la mayoría de los locutores, utilizando para ello palabras con carga semántica negativa ("hechos perversos e innobles", "hechos tan deleznables", "hechos cobardes"). El procedimiento discursivo predominante para introducir las evaluaciones negativas es recurrir al discurso referido directo $^{33}$. Esto se evidencia sobre todo en el género discursivo noticias, lo que permite reportar los juicios de valor a enunciadores determinados. De esta manera, en las noticias se encuentra la palabra del experto, del sacerdote, del pastor, de los feligreses, de los parlamentarios, que el redactor de noticias hace dialogar para construir una determinada interpretación del texto. Como señala Alice Krieg-Planque (citada en Moirand 2007), en los textos periodísticos se encuentran y dialogan personas que físicamente nunca se han conocido y que, de pronto, se encuentran interactuando bajo la tutela del redactor de noticias.

Nótese que en el ejemplo (3), el subsecretario del interior utiliza una "negación polémica", en el sentido de Ducrot (1984), que permite movilizar el discurso de reivindicación de tierrras sostenido por numerosas organizaciones mapuches, tal como lo vimos en el apartado precedente. Mediante la "negación polémica", el sujeto enunciador intenta fijar el sentido de su toma de palabra, descartado de plano la relación entre "quema de iglesias" y "reivindicaciones históricas del pueblo mapuche".

El acontecimiento "quema de iglesias" como terrorismo o acción terrorista

(4) "En esa causa (quema de iglesias), abierta por incendio terrorista" ( $\mathrm{La}$ Tercera, 1 de abril de 2016; Germán Becker, Diputado por Temuco y Padre Las Casas).

(5) "Es un hecho preocupante y sus acciones deberían considerarse terroristas" (La Tercera, 26 de abril de 2016; Germán Becker, Diputado por Temuco y Padre Las Casas).

32 En una declaración pública esta organización señaló: "No compartimos la quema de iglesias, pues consideramos que no apuntan al problema estructural, más bien agudizan la política represiva y deslegitiman nuestra digna lucha. Por tanto es importante desarrollar una estrategia de resistencia y sabotaje que le dé claridad a nuestras acciones y sean un real aporte en nuestro proceso de reconstrucción nacional" (EMOL, 16 de abril de 2016).

33 También conocido en literatura como estilo directo. Para una mayor profundización de este concepto, véase la entrada Discurso referido en el Diccionario de Análisis del Discurso (Charaudeau y Maingueneau 2002). 
(6) "Algunos de estos atentados sí obedecen a actos terroristas" ( $\mathrm{La}$ Tercera, 2 de abril de 2016; Alberto Espina, Senador por la Región de La Araucanía).

(7) "No entiendo cómo insisten en argumentar que esto no es terrorismo, cuando se ataca la fe de las personas" (La Tercera, 28 de julio de 2016; Gloria Naveillán, Dirigente de los agricultores de Malleco).

(8) "A esta organización se la nombre como una asociación ilícita terrorista" (La Tercera, 28 de julio de 2016; José Manuel Edwards, Diputado).

Otro tópico recurrente al momento de categorizar los acontecimientos relativos a la "quema de iglesias" dice relación con la utilización de la palabra terrorismo. Este vocablo nos remite a un "dominio de memoria" (Moirand 2007) acerca de la historia reciente en Chile, específicamente al trauma generado por la dictadura de Pinochet que categorizó como "terroristas" a los partidos de izquierda. En este sentido, la palabra "terrorista" se transformó en una verdadera "arena de lucha", en sentido de Bajtín (1970), debido a que funciona como un argumento que permite deslegitimar una acción determinada al mismo tiempo que desacredita a los agentes responsables de esta. Volveremos sobre esto más adelante.

En el ejemplo (7) se evidencian las vacilaciones al momento de categorizar de terrorismo las acciones relacionadas con la "quema de iglesias". Para los parlamentarios de derecha, los agricultores de la zona y las empresas forestales, se trata de acciones calificadas de terrorismo. Sin embargo, para el gobierno y varios parlamentarios de centro izquierda se trata de acciones de "delincuencia rural" o "delincuencia común", evitando el calificativo de "delito terrorista". Al igual que en (3), el sujeto enunciador utiliza la "negación polémica" (Ducrot 1984), lo que permite la emergencia del contradiscurso, a saber, el discurso sostenido por numerosos parlamentarios de centro izquierda e independientes que niegan la existencia de un delito terrorista. Cabe señalar a este respecto que la justicia chilena ha aplicado la ley antiterrorista en varias ocasiones a partir de 1998, abriendo un amplio debate sobre la pertinencia de esa ley heredada de la dictadura ${ }^{34}$.

Nótese la manera cómo aparece en los textos la designación de terrorismo: "incendio terrorista", "acciones terroristas", "actos terroristas" y "asociación ilícita terrorista". Las tres primeras construcciones (4), (5) y (6) califican una acción, mientras que la última (8) designa a una entidad, una organización. 
De este modo, se observa que el vocablo "terrorista" posee diferentes actualizaciones en el "hilo horizontal del discurso"35, lo que da cuenta de la dinámica asociativa de esta palabra en el discurso.

El acontecimiento "quema de iglesias" como acción violenta

(9) "Serie de hechos de violencia" (La Tercera, 26 de abril de 2016; Luis Arroyo, Fiscal jefe de la Unidad de Alta Complejidad de La Araucanía).

(10) "Se trata de una persona o de algún tipo de organización que se está adjudicando esta serie de hechos de violencia" (La Tercera, 26 de abril de 2016; Luis Arroyo, Fiscal jefe de la unidad de alta complejidad de la Araucanía).

(11) "Vamos a tener que refrescar los principios del Evangelio, porque si yo acepto a Cristo, la violencia no entra en mí" (El Mercurio, 17 de abril de 2016; Daniel Monsalve, Presidente del congreso evangélico de la provincia de Arauco).

(12) "El acto de cobardía de premiarse con impunidad frente a gente que no usa la violencia para proclamar aquello en lo que cree" (El Mercurio, 2 de mayo de 2016; Humberto Lagos, Director Nacional de Asuntos Religiosos).

(13) "Gente de las mismas comunidades que usan la vía de la violencia para llamar la atención" (La Tercera, 20 de junio de 2016; Héctor Espinosa, Director general de la Policía de Investigaciones).

La "quema de iglesias" vista como un fenómeno violento corresponde a otro tópico dominante en los textos analizados. Las nominalizaciones "serie de hechos de violencia" y "la violencia" aparecen de manera frecuente y vienen acompañadas muchas veces de descripciones detalladas de los hechos calificados de violentos que pueden abarcar un párrafo entero. Nótese la frecuencia de verbos introductorios "usar" que antecede al término violencia, como se ve en (12) y (13), y que nos orienta hacia los agentes responsables de la violencia. En los ejemplos mencionados anteriormente, no aparecen explícitamente los responsables de tales actos. El lector debe inferir a partir de los elementos entregados en los textos. Solo en el ejemplo (13) se observa una alusión explícita de los responsables, "gente de las mismas

35 El "hilo horizontal" y el "hilo vertical" del discurso corresponden a expresiones utilizadas por Pêcheux (1975). El hilo vertical del discurso corresponde al espacio donde interviene el "interdiscurso". Por su parte, el hilo horizontal corresponde al dominio de la sintaxis, en la que se puede observar el "intradiscurso". Para una mayor profundización de estos conceptos, y su posterior evolución, véase el Diccionario de Análisis del Discurso de Charaudeau y Maingueneau (2002). 
comunidades". Este agente es construido de manera negativa como un sujeto que busca solamente cobertura mediática.

Véase la presencia de la dimensión religiosa en (11), en la que el representante de la Iglesia evangélica hace un llamado de atención sobre la incompatibilidad entre cristianismo y la violencia. Este elemento no es algo banal, debido a que, como se verá más adelante, la dimensión religiosa ocupa una plaza importante en la construcción del acontecimiento "quema de iglesias" a través de las palabras perdón, culpa y rezo.

Nótese igualmente la presencia de la "negación polémica" (Ducrot 1984) en (12), que permite la emergencia de un contradiscurso que sostiene que hay grupos sociales que defienden sus ideas sin recurrir a la violencia. Esto último permite desarrollar la tensión en el discurso entre aquellos que defienden sus ideas a través de la violencia y quienes no utilizan la violencia para sostener su pensamiento.

El acontecimiento "quema de iglesias" como acción de un agente perverso

(14) "Esto no es reivindicación de tierras. Son personas enfermas y solo lo que nos queda es rezar por ellas" (El Mercurio, 13 de abril de 2016; Edmundo Espejo, feligrés).

(15) "Estamos pagando culpas de otros. Nosotros no tenemos pecado alguno" (El Mercurio, 13 de abril de 2016; Cristian Flores, feligrés).

(16) "Enemigos de los derechos humanos" (El Mercurio, 2 de mayo de 2016; Humberto Lagos, Director Nacional de Asuntos Religiosos).

(17) "Tenemos antecedentes de que son los grupos delincuenciales de siempre que vienen operando" (EMOL, 26 de abril de 2016; Daniel Monsalve, Presidente del Congreso Evangélico de la provincia de Arauco).

(18) "Tengo dudas de que este grupo realmente exista, pero si existe, y tiene la extensión territorial para cometer estos atentados, es un hecho preocupante y sus acciones deberían considerarse terroristas" ( $L a$ Tercera, 26 de abril de 2016; Germán Becker, Diputado por Temuco y Padre Las Casas).

En estos extractos se puede evidenciar la construcción de un otro negativo mediante una serie de designaciones calificantes: "personas enfermas", "enemigos de los derechos humanos", "grupos delincuenciales de siempre", etc. En el ejemplo (14), se puede apreciar el uso de la "negación polémica" (Ducrot 1984), que permite la emergencia de un contradiscurso que es neutralizado y que apunta a las históricas reivindicaciones territoriales de las comunidades mapuches desde inicios del siglo XX, tal como lo vimos anteriormente. Otro elemento que llama la atención es la confluencia de las 
dimensiones religiosas y judiciales cuando se aborda el tema. La dimensión religiosa se evidencia en los ejemplos (14) y (15), a través de las palabras "culpa", "rezar" y "pecado", articulando de este modo una red de relaciones semánticas que nos remiten a un universo religioso. Por su parte, la dimensión judicial se presenta de manera permanente en los textos, atravesando todo el discurso de la prensa ${ }^{36}$, y que se evidencia en (17) con las palabras "antecedentes" y "grupos delincuenciales de siempre".

La inclusión de la dimensión religiosa, a través del discurso referido de los feligreses y dirigentes de iglesias, permite la construcción de un "otro" que desconoce los valores cristianos como la solidaridad, el amor y la caridad. Esto último posee una gran importancia en Chile, que se reconoce como un país de fuertes raíces cristianas ${ }^{37}$ y donde la esfera religiosa permea otras dimensiones del mundo social.

Otro aspecto relevante de este apartado dice relación con la identidad de los autores de tales acciones. Esto se puede evidenciar en el ejemplo (18), en la que se cuestiona la identidad de los responsables de los hechos. Tal como se vio en el apartado consagrado al contexto histórico, la prensa designa al grupo Weichan Auka Mapu como responsables de la "quema de iglesias". Las expresiones que anteceden la presentación de este nombre propio son "grupo autodenominado", "supuesto grupo rebelde", lo que da cuenta de las dudas y vacilaciones de los redactores de noticias al momento de nombrar a los autores de los hechos.

El acontecimiento "quema de iglesias" como parte del conflicto mapuche

(19) "Se fijan mucho en los fenómenos puntales que van ocurriendo (atentados), pero les falta reconocer que este es un tema político que requiere una definición de Estado sobre el trato hacia el pueblo mapuche" (El Mercurio, 17 de abril de 2016; Fernando Chomalí, Obispo de Concepción).

(20) "Hay un malestar generalizado en la zona por la precaria situación de sus habitantes" (El Mercurio, 17 de abril de 2016; Fernando Chomalí, Obispo de Concepción).

36 Para Bengoa (2000), en el llamado "conflicto mapuche" se suele resaltar la dimensión judicial sobre la política y lo social. Esto ha llevado al autor a denunciar la excesiva judicialización del conflicto en La Araucanía.

37 El censo de 1990 declara que el $90 \%$ de los chilenos se consideraba católico. Posteriormente, el mismo censo arrojó que en en 2012 el $67 \%$ de la población se consideraba católica y cerca de un $18 \%$ evangélica. Para un mayor desarrollo, véase más https:// politicaspublicas.uc.cl/wp-content/uploads/2015/02/serie-n59-en-que-creen-los-chilenosnaturaleza-y-alcance-del-cambio-religioso-en-chile.pdf. 
(21) "Nos provoca un dolor inmenso, en donde el conflicto va tomando otros carices, y se va perjudicando a la propia comunidad mapuche" (La Tercera, 6 de abril de 2016; Cristian Rapiman, Presbítero).

(22) "Esto no escapa a lo que pasa en general, en que queman casa, galpones, pero con este matiz religioso" (El Mercurio, 13 de abril de 2016; Obispo Stegmeier).

El acontecimiento "quema de iglesia" como parte del "conflicto mapuche" corresponde a otro fenómeno recurrente en nuestros análisis. En efecto, como se aprecia en (19), el Obispo de Concepción intenta ir más allá de la coyuntura y aboga por una comprensión política del conflicto a largo plazo. Esto implica, en la lógica de Chomalí, reconocer que se trata de un fenómeno histórico y que es el resultado de la relaciones que se han establecido entre el pueblo mapuche y el Estado de Chile, al mismo tiempo que critica el tratamiento superficial del conflicto centrado en fenómenos específicos. Estas reflexiones de locutores autorizados son poco frecuentes en nuestro corpus debido a que la prensa escrita, en general, no realiza explicaciones históricas y sociales sobre el conflicto chileno mapuche. De hecho, cuando la prensa escrita aborda los acontecimientos "quema de iglesias" suele mencionar por medios de estadísticas los hechos de carácter violentos acontecidos en La Araucanía.

En el extracto (20) se puede apreciar la opinión del Obispo de Concepción a propósito de la situación de pobreza y desencanto que viven los habitantes de la zona, lo que da a entender que este conflicto se arrastra por largo tiempo. En (21), el presbítero Cristian Rapiman se lamenta de las nuevas dimensiones que va tomando el conflicto entre el Estado, los mapuches, las empresas forestales y los agricultores, lo que implica reconocer un conflicto preexistente al interior del cual se inscriben los acontecimientos relativos a la "quema de iglesias". Estos últimos, según Rapiman, son concebidos como una nueva faceta de un conflicto de larga duración entre el Estado de Chile y el pueblo mapuche. Nótese el ejemplo (22), en el cual obispo Stegmeier da una explicación sobre los acontecimientos, situando al mismo nivel la quema de casas, galpones e iglesias. A la luz de la teoría de la nominación, se trata de un esfuerzo para dar sentido a estos acontecimientos calificados de "incomprensibles" por la Iglesia católica y, de este modo, se reintroduce en un orden establecido aquello que parecía caótico y carente de lógica. 


\subsection{LA CONSTRUCCIÓN DEL MAPUCHE EN EL ACONTECIMIENTO "QUEMA DE IGLESIAS"}

En el transcurso de los acontecimientos "quema de iglesias", la prensa escrita representó a través del discurso a diferentes participantes, tales como los mapuches, el gobierno, la iglesia (tanto católica como evangélica), los feligreses, los carabineros y las organizaciones mapuches. Por razones de espacio, solo abordaremos la construcción discursiva de los mapuches.

El procedimiento para describir la representación de los mapuches sigue la línea de Mortureux (1993) y Moirand (2007, 2009), que utilizan el "paradigma de la designación" para referirse "a listas de sintagmas (en general nominales, a veces verbales) que funcionan en correferencia con un vocablo inicial en un discurso dado" (Mortureux 1993: 124). Bajo esta lógica, mediante el proceso de reformulación de un objeto del discurso (un agente, por ejemplo) se va a crear una asociación temporal entre una expresión y un elemento de la realidad social.

(23) "Son personas enfermas" (El Mercurio, 13 de abril de 2016; Edmundo Espejo).

(24) "Enemigos de los derechos humanos" (El Mercurio, 2 de mayo de 2016, Humberto Lagos).

(25) "En la medida en que haya grupos (mapuche) que están procediendo al mismo estilo que lo que pasó por allá por los años 40 en la Alemania nazi" (El Mercurio, 2 de mayo de 2016, Humberto Lagos).

(26) "Los autores tienen el acto de cobardía de premiarse con impunidad frente a gente que no usa la violencia..." (El Mercurio, 2 de mayo de 2016, Humberto Lagos).

(27) "Acá con los mapuches tengo una relación muy linda", dijo García. "Quien dice que después no ataquen colegios o postas. Hay que tomar esto con mucha serenidad. Solo nos queda rezar por el diálogo" ( $E l$ Mercurio, 13 de abril de 2016, Óscar García, párroco).

La construcción discursiva de los mapuches ha sido estudiada de manera robusta por el equipo de Merino et al. (2007) desde el Análisis Crítico del Discurso. En estos trabajos se enfatiza la construcción negativa de "los mapuches" por la prensa escrita a través de una serie de procedimientos a nivel léxico, sintáctico y semántico. Esta investigación confirma los hallazgos del equipo de Merino et al. (2007) en cuanto a dicha construcción negativa. En el corpus analizado, se evidenció la caracterización del actante "los mapuches" con una serie de adjetivos y sintagmas nominales de carga semántica negativa, tales como "personas enfermas", "enemigos de los derechos humanos", "delincuentes", "terroristas", "violentistas", "grupos 
violentistas", "encapuchados", y "grupos delincuenciales de siempre", entre otros.

En (23), (24) y (26), se puede observar una serie de designaciones calificativas sobre los responsables de la "quema de iglesias". Si bien no se hace alusión explícita acerca de los autores de estas acciones, se establece un vínculo directo entre los panfletos que aluden a la causa mapuche encontrados en el sitio del suceso y la "quema de iglesias", como se evidencia en este extracto:

En el lugar -según consigna radio Bío Bío- también se encontró un lienzo alusivo a la causa mapuche y un panfleto en el que se lee una amenaza: "Todas las iglesias serán quemadas. Fuera!!! Libertad a los Presos políticos Mapuches" (Publimetro, 01/04/2016).

Como se puede observar, la existencia de un lienzo a favor de la causa mapuche y de un panfleto con un contenido amenazador para el Estado de Chile permite establecer la relación causa-efecto entre las demandas mapuches no satisfechas y la acción de quemar iglesias. Esto trae como consecuencia la estigmatización de la población mapuche, en el sentido de Goffman (1970), vista como violenta y amenazadora para la sociedad chilena, como en (27). Nótese la construcción semántica de (27), cuya primera parte del enunciado destaca la relación afectiva que Óscar García posee con los mapuches, mientras que la segunda parte del enunciado ${ }^{38}$ representa discursivamente al mapuche como una amenaza para la sociedad chilena mediante la expresión "quien dice que después no ataquen colegios o postas". Este punto resulta fundamental, debido a que por medio de discurso se construye un "otro" generalizado, que no discrimina entre mapuches que reivindican la violencia y quienes no.

Destaquemos finalmente la comparación que establece en (27) entre los responsables de la "quema de iglesias" y el accionar de los nazis, tal como lo establece Humberto Lagos, director de la Oficina de Asuntos Religiosos. Mediante la utilización del discurso referido directo, el redactor de noticias otorga la palabra a un experto chileno, quien nos remite a un "dominio de memoria" al comparar los acontecimientos en torno a la "quema de iglesias" con el nazismo, con el objetivo pragmático de desacreditar a los actores responsables.

38 Como señala Ducrot (1984), en los enunciados compuestos por dos proposiciones, la segunda parte del enunciado siempre es más relevante que la primera. 


\subsection{LA MEMORIA Y LA MANERA DE DESIGNAR A LOS PARTICIPANTES}

En este apartado analizaremos la contribución de la noción de memoria trabajada desde el Análisis del Discurso de origen francés. Tal como se vio en el apartado 4.3, la memoria se inscribe en el discurso, según Moirand $(2003,2007)$, esencialmente a través de formas léxicas. En nuestro corpus se evidenció ciertos grupos nominales como "incendio terrorista", "acciones terroristas", "actos terroristas" y "asociación ilícita terrorista", que nos remite a un tiempo histórico dominado por el totalitarismo de derecha, en la que la palabra "terrorista" designaba al enemigo comunista. Esto explica las discusiones actuales de los diferentes sectores políticos en torno a la palabra "terroristas", que se transforma en una verdadera "arena de lucha" en el sentido bajtiniano, debido a que esta posee una carga semántica negativa que desacredita cualquier acción, así como a los agentes responsables de estas.

Otra construcción que nos remite a un "dominio de memoria" corresponde a la nominalización "la causa mapuche". Esta construcción se inscribe dentro de un "tiempo corto", en el lenguaje de Braudel (1986), correspondiente a los acontecimientos recientes asociados a "la causa mapuche" por la prensa chilena: violencia, incendios de camiones e iglesias, pobreza y desigualdad. De la misma forma, esta nominalización nos remite a un "tiempo largo" (Braudel 1986), que nos conduce a los orígenes del conflicto que datan del siglo XIX, tal como lo vimos, y que se actualizan en el discurso mediante el uso de esta expresión y sus dervidados, tales como "la causa indígena", "el conflicto indígena", "la cuestión mapuche".

Mencionemos también otras expresiones como "otro atentado en la Araucanía", "nuevo atentado en la Araucanía", que aparecen generalmente en los titulares de las noticias y que nos conduce igualmente a un "dominio de memoria". El análisis de los términos "otro" y "nuevo" seguido de un sustantivo ha sido estudiado por Krieg-Planque (2009b), en relación con la construcción discursiva de lo que ella denomina "nombres propios de acontecimientos". Según esta autora (2009b), los "nombres propios de acontecimientos" poseen estructuras regulares identificables en la superficie textual $^{139}$, que permiten, por un lado, responder a las necesidades de categorización que poseen los medios de comunicación y, por otro lado, establecer relaciones de comparación y analogía entre los acontecimientos

\footnotetext{
39 Krieg-Planque (2009b) identificó varias formas, entre ellas: deter. $+\mathrm{N}+$ adj.con valor clasificante "un Tchernobil químico"; deter. $+(\operatorname{adj})+\mathrm{N}+$ sintagma preposicional "un pequeño mayo 68 de las periferias"; deter.+ otro + N "un otro 7marzo"; deter. + nuevo + N "un nuevo 21 de abril".
} 
que "son puestos en perspectiva". En lo que respecta a las expresiones "otro atentado" y "nuevo atentado" seguido de un topónimo, se puede constatar en nuestro corpus la práctica discursiva de los redactores de prensa de categorizar y relacionar hechos similares. Esto permite configurar una serie de relaciones semánticas entre los diferentes temas abordados en los textos (violencia, inseguridad, impunidad y búsqueda de paz), que nos remite a un "tiempo corto" y a un "tiempo largo" (Braudel 1986), tal como se observó en el sintagma "la causa mapuche".

Analicemos finalmente la comparación que establece Humberto Lagos en el extracto (27) al relacionar los acontecimientos "quema de iglesias" con el nazismo. La referencia a un tiempo histórico es evidente y permite movilizar en la memoria de los lectores un conjunto de imágenes vinculadas con el nazismo (intolerancia, violencia, guerra, exterminio, etc.), que vienen a desacreditar a los responsables de la "quema de iglesias", al mismo tiempo que otorga inteligibilidad a estos acontecimientos. En este sentido, se trata de una comparación que posee un efecto pragmático y que funciona sobre la base de un conocimiento histórico socialmente compartido que se activa mediante uso de esta expresión.

\section{CONSIDERACIONES FINALES}

La construcción desde un punto de vista discursivo del acontecimiento denominado "quema de iglesias" contribuye a la reflexión sobre tres fenómenos.

En primer lugar, la manera en que la prensa escrita aborda este acontecimiento. Se destacan en nuestro corpus los hechos vinculados con la violencia, la inseguridad, el terrorismo y el orden público en general, en lugar de ofrecer una comprensión histórica o social del fenómeno. Si bien la prensa utiliza construcciones nominales que movilizan un "dominio de memoria", tales como "la cuestión mapuche", "el conflicto indígena", "otro atentado en la Araucanía" y "un nuevo atentado en La Araucanía", estas no ofrecen una explicación histórica y social del origen del conflicto y de los intereses de los diferentes actores involucrados. En el lenguaje de Braudel (1986), se trata de dar cuenta de un "tiempo corto" relativo a los últimos hechos en la zona de La Araucanía. Cabe señalar al respecto que el tratamiento parcial y polarizado de los conflictos sociales es un fenómeno recurrente en la prensa escrita (Moirand 2007; Charaudeau 2003). En esta perspectiva, los 
diferentes artículos de prensa (noticias, editoriales, columnas, entrevistas y reportajes) corresponden a "objetos de venta" (Moirand 2007) que están sujetos, según Charaudeau (2003), a una lógica comercial y cultural, que determina sus condiciones sociales de producción.

En segundo lugar, resaltar la construcción negativa del participante "mapuche" en nuestro corpus. Como se señaló, este resultado sigue la línea de los trabajos de Merino et al. (2007), quien, desde la perspectiva del Análisis Crítico del Discurso, constató este hallazgo en cuatro corpus diferentes (discurso de la prensa, manuales escolares, discurso público y discurso cotidiano). Nos parece interesante prolongar esta discusión incorporando las nociones de imaginarios sociales (Castoriadis 1989) y las representaciones sociales (Jodelet 1986) con el fin de responder a las siguientes interrogantes: ¿cuáles son los imaginarios y las representaciones sociales que se construyen a partir de este discurso?, ¿cómo circulan estas representaciones? y ¿de qué manera estas representaciones inciden en el debate público a propósito del conflicto en La Araucanía? Esto nos permitiría explorar un terreno poco abordado y, de esta manera, proponer una mejor articulación entre los aspectos discursivos y sociales.

En tercer lugar, creemos pertinente preguntarnos sobre las consecuencias éticas y sociales al designar a los mapuches como "terroristas", "delincuentes" o al comparar el accionar de los responsables de la "quema de iglesias" con los nazis. Una manera de responder a estas interrogantes es por medio del concepto de "ética lingüística", desarrollado por Moirand y Porquier (2005), que nos remite en último término a la relación entre lenguaje y moral ${ }^{40}$. Estos autores se preguntan sobre las consecuencias que poseen la práctica discursiva en la esfera social, así como sobre la responsabilidad de la prensa al momento de realizar comparaciones y asociaciones que podrían denostar la integridad de un grupo humano. Bajo esta óptica, calificar de terroristas a ciertas organizaciones mapuches o de vincular sus acciones con las del nazismo, sin tomar en cuenta sus efectos en el mundo social evidencia una carencia de una "ética lingüística", en sentido de Moirand y Porquier (2005). En especial cuando el comportamiento discursivo de la prensa participa en la estigmatización de la población mapuche, reforzando de este modo ciertas construcciones estereotipadas sobre estos últimos. 


\section{REFERENCIAS BIBLIOGRÁFICAS}

Achugar, Mariana. 2011. Aproximaciones dicursivas a la transmisión intergeneracional del pasado reciente. En Teresa Oteíza y Derrin Pinto (eds.). En (re)construcción: discurso, nación e identidad en los manuales escolares, pp. 43-88. Chile: Editorial Cuarto Propio.

Bajtín, Misaíl. 1970. La poétique de Dostö̈evski. Paris: Seuil.

BENGOA, José. 2000. Historia del pueblo mapuche (siglo XIX X XX). Santiago: Lom Ediciones.

Bonnafous, Simone y Maurice Tournier. 1995. Analyse du discours, lexicométrie, communication et politique. Langages 29: 67-81.

Branca-Rosoff, Sonia. 2007. Approche discursive de la nomination/dénomination. En Georgeta Cislaru, Olivia Guérin, Katia Morim, Émilie Née, Thierry Pagnier y Marie Veniard (eds.). L'acte de nommer. Une dynamique entre langue et discours, pp. 13-22. Paris: Presses Sorbonne Nouvelle.

Braudel, Fernand. 1986. La historia y las ciencias sociales. Madrid: Alianza.

Calabrese, Laura y Laurence Rosier. 2005. Conflit d'intérêt et crise discursive: la canicule de l'été 2003. Réseaux 100: 19-43.

Calabrese, Laura. 2013. L'événement en discours. Presse et mémoire sociale. Louvain-laNeuve: Académia-L'Harmattan.

Castoriadis, Cornelieus. 1989. La Institución Imaginaria de la Sociedad. Buenos Aires: Tusquets Editores.

Charaudeau, Patrick y Dominique Maingueneau. 2002. Dictionnaire d'analyse du discours. Paris: Seuil.

Charaudeau, Patrick. 2003. El discurso de la información. Barcelona: Gedisa.

Courtine, Jean-Jacques. 1981. Analyse du discours politique. Langages 62, s/p.

Détrie, Catherine; Paul Siblot y Vérine Bertrand (eds.). 2001. Termes et concepts pour l'analyse du discours. Une approche praxématique. Paris: H. Champion.

Ducrot, Oswald. 1984. Le dire et le dit. Paris: Les Éditions de Minuit.

Goffman, Erving. 1970. Estigma: la identidad deteriorada. Buenos Aires: Amorrortu.

González, Claudia. 2012. Discurso televisivo y conflicto étnico chileno-mapuche. Perspectivas de la comunicación 2: 54-73.

Halbwachs, Maurice. 1997. La mémoire collective. Paris: Albin Michel.

HiRT, IRĖNE. 2001. El pueblo mapuche en la "era de la información”: ¿hacia la autonomía de los espacios de comunicación? [en línea]. Disponible en http://galeon.com/mapuexpress/ publicaciones/irene.htm\#_ednref2

Jodelet, Denise. 1986. La representación social: fenómenos, conceptos y teoría. En Serge Moscovici (comp.). Psicología Social II, pp. 478-494. Barcelona: Paidós.

Kleiber, Georges. 1984. Dénomination et relations dénominatives. Langages 76: 77-94.

Krieg-Planque, Alice. 2009a. La notion de "formule" en analyse du discours. Cadre théorique et méthodologique. Besançon: Presses Universitaires de Franche-Comté. 77-90.

2009b. À propos des "noms propres d'événement". Les Carnets du Cediscor 11:

Levil Chicahual, Rodrigo. 2006. La sociedad mapuche contemporánea. En Pablo Marimán, Sergio Caniuqueo, José Millalén y Rodrigo Levil Chicahual (eds.). ; ...Escucha winka...! Cuatro ensayos de Historia Nacional Mapuche y un epilogo sobre el futuro, pp. 219-249. Santiago, Chile: Lom Ediciones.

Marimán, Pablo. 2006. Los mapuches antes de la conquista militar chileno argentina. En Pablo Marimán, Sergio Caniuqueo, José Millalén y Rodrigo Levil Chicahual (eds.). ¡...Escucha winka...! Cuatro ensayos de Historia Nacional Mapuche y un epilogo sobre el futuro, pp. 53-126. Santiago, Chile: Lom Ediciones. 
Mella Seguel, Eduardo. 2007. Los mapuche ante la justicia. La criminalización de la protesta indigena en Chile. Santiago: Lom Ediciones.

Merino, María Eugenia; Mauricio Pilleux; Daniel Quilaqueo y Berta San Martín. 2007. Racismo discursivo en Chile. El caso Mapuche. En Teun van Dijk (ed.). Racismo y Discurso en América Latina, pp. 137-181. Madrid: Editorial Gedisa.

Moirand, Sophie. 2003. Les lieux d'inscription d'une mémoire interdiscursive. En Juhani Härmä (ed.). Le langage des médias: des discours éphémères?, pp. 83-111. Paris: l' Harmattan.

2007. Les discours de la presse quotidienne. Observer, analyser, comprendre.

Paris: PUF.

2009. Des façons de nommer "les jeunes" dans la presse quotidienne nationale. Adolescence 70: 907-919.

y Rémy Porquier. 2005. De l'éthique de la nomination à l'éthique de l'interprétation: autour du mot "otage" et de quelques autres. En Régine Delamotte-Legrand y Claude Caitucoli (eds.). Morales langagières Autour de propositions de recherche de Bernard Gardin, pp.139-154. Rouen: Publication des Universités de Rouen et du Havre.

Monckeberg, María Olivia. 2003. El imperio del Opus Dei en Chile. Santiago: Ediciones B Chile S.A.

Mortureux, Marie-Françoise. 1993. Paradigmes désignationnels. SEMEN 9: 121-141.

Pairicán, Fernando. 2013. Lumaco: la cristalización del movimiento autodeterminista mapuche. Revista de Historia Social y de las Mentalidades 17: 35-57.

Paveau, Marie Anne. 2006. Les Prédiscours. Sens, mémoire, cognition. Paris: Presses Sorbonne nouvelle.

2013. Langage et morale. Une éthique des vertus discursives. Paris: Lambert-Lucas.

Pêcheux, Michel. 1975. Les vérités de La Palice. Linguistique, sémantique, philosophie. Paris: Maspero.

Pinto, Jorge (ed.). 2015. Conflictos étnicos, sociales y económico. Araucanía 1900-2014. Santiago, Chile: Pehuén.

2003. La formación del Estado y la nación y el pueblo mapuche. De la inclusión a la exclusión. Santiago, Chile: Dirección de Bibliotecas, Archivos y Museos (DIBAM).

2017. Violencia en la Araucanía entre 1990-2007. Conferencia presentada en el seminario "Wallmapu y Violencia. Debates y tensiones en torno a la situación Mapuche actual", Departamento de Historia de la Universidad de Concepción, Concepción.

Quéré, Louis. 2013. Les formes de l'événement. Mediazoni 15 [en línea]. Disponible en http://www.mediazioni.sitlec.unibo.it/images/stories/PDF_folder/document-pdf/15-2013/ qur.pdf

SaAvedra, Alejandro. 2002. Los mapuches en la sociedad actual. Santiago, Chile: Lom Ediciones.

Segovia Lacoste, Pablo. 2005. Semántica de la guerra en el conflicto mapuche. En Mauricio Pilleux (ed.). Contextos del discurso, pp. 87-100. Valdivia: Universidad Austral de Chile.

2015. Nommer le 'conflit mapuche' dans la presse chilienne. En Richard Arnaud, Fred Hailon y Nahida Guellil (eds.). Le discours politique identitaire dans les médias, pp. 139-165. Paris: L' Harmattan.

2016. La construction discursive de l'événement conflit mapuche dans la presse écrite chilienne. Synergies Chili 12: 73-87.

; Óscar Basulto Gallegos y Pablo Zambrano Uribe. 2018. Imaginarios sociales y representaciones: una aplicación a análisis discursivos en tres ámbitos diferentes. Empiria 41: 79-102. 
Siblot, Paul. 1997. Nomination et production de sens: le praxème. Langages 127: 38-55. 2001. De la dénomination à la nomination. Les dynamiques de la signifiance nominale et le propre du nom. Cahiers de praxématique 36: 89-214.

Tricot, Tito. 2013. Autonomía. El movimiento Mapuche de resistencia. Santiago, Chile: CEIBO.

Veniard, Marie. 2013. La nomination des événements dans la presse. Essai de sémantique discursive. Paris: Presses universitaires de Franche-Comté.

Wolton, Dominique. 1995. La communication politique. Hermès 17/18: 9-13. 